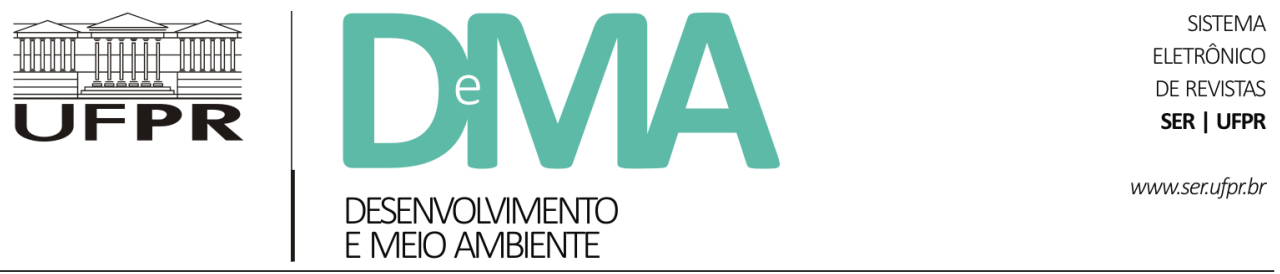

\title{
Antecedentes da Lei Federal de Agrotóxicos (7.802/1989): o protagonismo do movimento ambientalista no Rio Grande do Sul
}

\section{The Brazilian Federal Law of Pesticides (7.802/1989): the Protagonism of the Environmental Movement from Rio Grande do Sul}

\author{
Caroline da Rocha FRANCO ${ }^{1}$, Victor PELAEZ ${ }^{2 *}$ \\ ${ }^{1}$ Instituto Federal do Paraná (IFPR), Curitiba, PR, Brasil. \\ ${ }^{2}$ Universidade Federal do Paraná (UFPR), Curitiba, PR, Brasil. \\ *E-mail de contato: victormpelaez@gmail.com
}

Artigo recebido em 18 de outubro de 2016, versão final aceita em 01 de agosto de 2017.

RESUMO: Este artigo faz um retrospecto histórico sobre a importância do movimento ambientalista no Rio Grande do Sul na criação da primeira lei estadual de agrotóxicos do país, em 1982. A Associação Gaúcha de Proteção ao Ambiente Natural, sob a liderança de José Lutzenberger, teve papel preponderante na criação de uma agenda de combate ao uso dos agrotóxicos no Rio Grande do Sul. A legislação permitiu maior controle sobre a aprovação e o uso de agrotóxicos, com a introdução de importantes dispositivos legais: a autorização de produtos agrotóxicos condicionada ao uso aprovado nos países de origem, a classificação toxicológica dos produtos autorizados, o direito de entidades civis de impugnar registros de produtos que apresentem risco à saúde da população e a exigência do receituário agronômico. A aprovação e a implementação dessa lei foram objeto de intensa resistência da parte da indústria de agrotóxicos, que buscou desqualificá-la judicialmente por meio de representação de inconstitucionalidade no Supremo Tribunal Federal. A mobilização de grupos organizados da sociedade civil contribuiu para a difusão desse instrumento de controle social a outras unidades da federação, e a experiência adquirida por alguns dos integrantes do movimento ambientalista gaúcho, na constituição da lei estadual, influenciou significativamente na elaboração e na aprovação da Lei Federal de Agrotóxicos n. 7.802/1989. Tal experiência, aliada a um momento histórico favorável à inclusão da questão ambiental na agenda política do governo federal, foi determinante para o avanço do Brasil na normatização de substâncias que oferecem perigo à saúde humana e ao meio ambiente.

Palavras-chave: agrotóxicos; lei; Rio Grande do Sul.

ABSTRACT: This paper gives a historical review of environmentalist movement importance in Rio Grande do Sul State, concerning the creation of the first pesticide state law in 1982. The Rio Grande do Sul Association of 
Environmental Protection, under Lutzenberger's leadership, had a preponderant role on the agenda setting against pesticide use in RS. The legislation allowed a stricter control in the approval and use of pesticides through the introduction of important legal devices: the authorization of pesticides conditioned to their former approval in the countries of origin, the toxicological classification of pesticides, the civil organizations' rights to contesting registrations of products that may cause risk to human health, and the request of agronomic prescription. The approval and implementation of the state law was subject to the intense resistance from the pesticide industry, which contested its constitutionality at the Brazilian Federal Supreme Court. The mobilization of organized groups of civil society contributed to the dissemination of this social control device to other federation states. The experience acquired by some members of the environmentalist movement in Rio Grande do Sul State had a decisive influence on the format of the Pesticide Federal Law 7.802/1989. Such an experience, in association with a favorable historical moment for the inclusion of environmental issues in the federal government political agenda, was determinant to the Brazilian advance in the regulation of harmful substances.

Keywords: pesticides; law; Rio Grande do Sul.

\section{Introdução}

Ao substituir o Decreto Federal n. 24.114/1934, a Lei Federal n. 7.802/1989, conhecida como Lei de Agrotóxicos, propiciou grande avanço institucional, particularmente em relação à proteção à saúde humana e à preservação do meio ambiente. Essa legislação estabeleceu, entre outras medidas, proibição do registro de novos agrotóxicos caso a ação tóxica destes não fosse igual ou menor que a de outros produtos já existentes destinados a um mesmo fim; possibilidade de impugnação ou cancelamento do registro por solicitação de entidades representativas da sociedade civil; cadastro compulsório de produtores, comerciantes e aplicadores dos produtos nos órgãos competentes dos estados ou municípios, no intuito de maior rastreabilidade das infrações causadas pelos agrotóxicos; criação de normas e padrões das embalagens, assim como normas, padrões e instruções dos rótulos dos produtos; atribuição de responsabilidades administrativas por qualquer dano causado pelos agrotóxicos; e obrigatoriedade do receituário agronômico para a venda de agrotóxicos, até então disposta apenas por normas de alguns estados.
Cabe ressaltar que a constituição desse marco legal foi fruto de um processo de mobilização de segmentos da sociedade civil iniciado no Rio Grande do Sul (RS), notadamente pelo ambientalista José Lutzenberger e pela Associação Gaúcha de Proteção ao Ambiente Natural (Agapan). As ações por eles protagonizadas levaram à criação de uma lei estadual no Rio Grande do Sul, em 1982, a qual estabeleceu pela primeira vez no país instrumentos de controle da comercialização e do uso de agrotóxicos. A experiência desse estado foi então disseminada para outras unidades da federação, notadamente Paraná, Santa Catarina e São Paulo, fator fundamental para que o controle do uso intensivo dos agrotóxicos entrasse na agenda política do governo federal no final dessa década.

O objetivo deste artigo é apresentar um histórico sobre o processo de criação da lei gaúcha de agrotóxicos e sua influência na elaboração da Lei Federal de Agrotóxicos. Nesse contexto, destacam-se duas posições antagônicas representativas de um debate caracterizado, de um lado, pela emergência de um movimento ambientalista crítico ao modelo agrícola adotado no país e, de outro, pela representação de interesses das empresas de agrotóxicos. Essa 
polarização de interesses foi identificada com base nas estratégias adotadas pelos grupos mais representativos à época-Agapan e Associação Nacional de Defensivos Agrícolas (Andef) -, no sentido de influenciar o processo de formulação de políticas públicas que antecederam a legislação federal.

As informações para a elaboração deste texto foram obtidas por meio de pesquisa bibliográfica em livros e artigos de jornais, que registraram a polêmica em torno da regulamentação de agrotóxicos à época. Foram também consultados os textos dos projetos de lei estadual e federal sobre o controle do uso de agrotóxicos e as exposições dos motivos das decisões dos parlamentares envolvidos. Além disso, foram realizadas entrevistas com três dos principais protagonistas do processo de elaboração e aprovação da lei de agrotóxicos no Rio Grande do Sul: Antenor Ferrari, ex-deputado estadual, autor do projeto de lei estadual; o agrônomo Sebastião $\mathrm{Pi}$ nheiro e o químico José Lewgoy, ambos integrantes da Agapan nas décadas de 1970 e 1980.

Este artigo está estruturado em mais seis seções. A segunda faz um breve histórico do movimento ambientalista gaúcho, protagonizado pela Agapan. A terceira explica como a questão dos agrotóxicos tornou-se um problema coletivo e adentrou a agenda política gaúcha, a fim de se estabelecer instrumentos institucionais de controle do uso desses produtos. A quarta expõe o processo de elaboração da legislação gaúcha e seus principais dispositivos de controle do uso de agrotóxicos. A quinta trata das estratégias de resistência da Andef, a fim de impedir a efetivação do novo marco legal no âmbito estadual. A sexta resgata as repercussões da lei de agrotóxicos do Rio Grande do Sul em nível federal, com a retomada da agenda ambiental pelo governo federal. Por fim, a última seção tece as considerações finais.

\section{A Associação Gaúcha de Proteção ao Ambiente Natural}

Em 27 de abril de 1971 foi oficialmente instituída a Associação Gaúcha de Proteção ao Ambiente Natural (Agapan), fruto da mobilização de naturistas ${ }^{1}$ reunidos pelo engenheiro agrônomo e ex-funcionário da Basf, José Lutzenberger. A entidade tinha desde o início uma estrutura organizada, na qual as tarefas administrativas estavam a cargo de Augusto César Cunha Carneiro, ex-militante do Partido Comunista Brasileiro (PCB), que cimentou a base de sustentação da Agapan (Bones \& Hasse, 2007). O carisma de Lutzenberger e o sentido de organização de Carneiro a tornaram um clube aberto em defesa da natureza, com reuniões públicas semanais. Nelas, os membros dedicavam considerável atenção às cartas de simpatizantes, às denúncias de sócios e colaboradores, atuando por meio de abaixo-assinados, palestras, debates, cursos e seminários (Bones \& Hasse, 2007).

O contexto histórico de militância da Agapan era o de construção de uma crítica à degradação ambiental nos meios urbano e rural, na qual incluía-se o questionamento ao modelo da Revolução Verde, baseado no uso intensivo de agrotóxicos. A atuação da Agapan foi muito dificultada durante o governo Médici, quando o clima repressivo que dominava o

\footnotetext{
${ }^{1} \mathrm{O}$ movimento conservacionista do Rio Grande do Sul esteve ligado à ação de naturistas. O naturismo representa um conjunto de princípios éticos e comportamentais que preconizam um modo de vida baseado na conservação da natureza e na defesa da vida ao ar livre, por meio do consumo de alimentos naturais e da prática do nudismo (Dreyer, 2004, p. 129-130).
} 
país tornou praticamente heroica qualquer organização autônoma da sociedade civil que não agisse sob o manto da Igreja Católica (Viola, 1987).

Embora as teses propagadas pela entidade fizessem com que muitos a considerassem como um grupo comunista, isso não impediu que Lutzenberger se tornasse uma figura influente, incitando profissionais a questionarem o uso desses insumos. Um agrônomo conquistado pela Agapan foi Sebastião Pinheiro, então funcionário da Cooperativa Tritícola Erechim (Cotrel), uma das poderosas cooperativas de agricultores da região de Erexim. Pinheiro era também engenheiro florestal e tinha conhecimento de química, além da preocupação com seu uso na agricultura, o que favoreceu sua aproximação com Lutzenberger. Ele se tornou referência no combate aos agrotóxicos, publicando livros sobre o tema. Em 1985, compôs a Comissão Especial de redação do anteprojeto, apresentado ao Congresso Nacional, relativo à criação da Lei Federal de Agrotóxicos.

As conferências de Lutzenberger foram transformadas em textos marcantes, tal como o intitulado Insensatez da agroquímica e o Contaminação insidiosa, que contaram com cópias impressas e distribuídas pela Sociedade de Agronomia do Rio Grande do Sul às entidades congêneres de todo o Brasil. As publicações refletiram em convites para palestras em diversos estados, resultando na difusão da pauta e na mobilização dos profissionais de agronomia em relação ao tema. A visão de Lutzenberger sobre os agrotóxicos chocou os profissionais que tomaram contato com suas teses, pois era quase impossível aceitar quebra tão violenta de tudo o que haviam aprendido a considerar como técnico, sensato e moderno. Como observa Dreyer (2004, p. 44),

Em 1975, a indústria química ameaçou processá-lo por ele ter classificado uma campanha publicitária da Andef, a Associação Nacional dos Fabricantes de Defensivos Agrícolas, como "ecopornografia". (...) Foi um dos raros momentos em que Lutz revelou sua condição de ex-funcionário da BASF para com isso aumentar o impacto de alguma declaração sua. Diante dos prepostos da Andef, porém, ele abriu uma exceção. Disse a eles que aguardava ansioso pela oportunidade de debater em público com a indústria certas questões sobre postura ética. O processo foi sustado.

Em 1978, Lutzenberger foi eleito Agrônomo do Ano pela Associação dos Engenheiros Agrônomos do Estado de São Paulo (AEASP), por 4 votos contra e 412 a favor (Dreyer, 2004). Embora não tenha atuado no corpo a corpo da campanha contra os agrotóxicos, devido à sua militância ser requisitada em muitos espaços ao mesmo tempo, Lutzenberger foi a referência do movimento e também o fiel da balança nos momentos de decisão. Seu conhecimento sobre o assunto e sua capacidade de liderança de um quadro qualificado de associados, como professores universitários, agrônomos, engenheiros, juristas e geneticistas, foram fundamentais para desencadear um debate tecnicamente qualificado sobre o uso crescente dos agrotóxicos no Rio Grande do Sul. Eles não só estruturaram textos com linguagem acessível sobre o tema, no intuito de difundir a perspectiva ambientalista, mas foram militantes que enfrentaram os interesses tanto da indústria de agrotóxicos quanto de frações do governo que defendiam a difusão do modelo de produção da Revolução Verde.

As diversas situações de confronto, preparadas pela Agapan, contribuíram para que esta mobilizasse considerável atenção da imprensa e de consumidores urbanos. Isso colaborou sobremaneira para sua visibilidade e destaque nos debates 
legislativos. As soluções ambientais defendidas, desde 1971, por Lutzenberger e seus companheiros atraíram a atenção dos governantes e fizeram com que a necessidade da proteção à saúde e ao meio ambiente adentrasse a agenda governamental, além de proporcionarem uma nova maneira de a sociedade analisar as implicações da opção pela agricultura baseada no uso intensivo de insumos químicos.

\section{A agenda gaúcha sobre agrotóxicos: a construção da lei estadual}

As mobilizações políticas e sociais que levaram à criação da Lei Estadual n. 7.747/1982, conhecida como Lei Gaúcha de Agrotóxicos, têm como um de seus componentes principais, se não o fundamental, a contaminação do Rio Guaíba, em maio de 1982, por produtos organoclorados usados como inseticidas nas culturas agrícolas da região. Esse evento aglutinou várias entidades representativas da sociedade ${ }^{2}$, que passaram a se reunir periodicamente com a Comissão de Direitos Humanos, órgão da Assembleia Legislativa do Estado, na qual estabeleceram um fórum sobre o tema (Ferrari, 1985).

O fórum tinha inicialmente três objetivos principais. Em primeiro lugar, reivindicava à Secretaria da Saúde e Meio Ambiente do Rio Grande do Sul a realização de estudos sobre os efeitos toxicológicos dos organoclorados, uma vez que não havia informações consistentes a respeito. Em segundo lugar, solicitava a proibição da comercialização e do uso, no território estadual, dos compostos organoclorados. Segundo Ferrari (1985, p. 53), as razões para tais reivindicações baseavam-se no fato de que

os organoclorados são produtos químicos de longa persistência, de ação cumulativa e pequena degradabilidade no ambiente, cujo consumo continuado implicaria a elevação dos Índices de contaminação das águas do Guaíba; (...) a Bacia do Jacuí, responsável pelo fornecimento de 35\% das águas do Guaíba, abrange uma área onde se verifica o mais elevado índice de utilização de organoclorados no Estado. A Bacia do Jacuí abrange 33\% da área do Estado e 66\% da população, ou seja, mais de 5 milhões de pessoas.

Em terceiro lugar, o fórum reivindicava a instituição do receituário agronômico (RA), com base na recomendação dos engenheiros agrônomos, que há anos debatiam o tema. Em abril de 1978, organizaram o $1^{\circ}$ Curso sobre Fundamentos do Receituário Agronômico, promovido pelo Centro Gaúcho de Estudos Toxicológicos, cujos anais foram publicados pela Sociedade de Agronomia do Rio Grande do Sul (Sargs) em conjunto com o Conselho de Desenvolvimento Agropecuário do Rio Grande do Sul. Nesse encontro, definiu-se o conteúdo da receita como "um conceito etiológico, diagnóstico definitivo obtido após a aplicação de uma metodologia ordenada" (Sampaio, 1978). Buscava-se que o engenheiro agrônomo, intermediário entre a indústria e o usuário, fosse além das infor-

\footnotetext{
${ }^{2}$ Participaram do evento Associação Democrática Feminina Gaúcha (ADFG); Centro de Estudos de Toxicologia do Rio Grande do Sul; Associação Gaúcha de Proteção ao Ambiente Natural (Agapan); Federação Riograndense de Associações Comunitárias e Moradores de Bairros (Fracab); Movimento de Justiça e Direitos Humanos; Sociedade de Agronomia do Rio Grande do Sul (Sargs); Sociedade de Engenharia; Instituto de Direito Ecológico; Fundação Balduíno Rambo; Associação dos Farmacêuticos Químicos (Afargs); Associação Gaúcha dos Sociólogos; Centro dos Professores do Estado do Rio Grande do Sul (CPERS); Associação de Preservação da Natureza do Vale Gravataí (APNVG); Instituto dos Arquitetos do Brasil (IAB) e Sindicato dos Arquitetos no Estado do Rio Grande do Sul (Saergs) (Ferrari, 1985).
} 
mações prestadas pelas empresas, visto que a prescrição do receituário agronômico exigia conhecimento dos processos semiotécnicos ${ }^{3}$, memorização rápida de conceitos, estudo contínuo da tecnologia disponível, análise dos aspectos ecológicos (locais e regionais) e dos reflexos toxicológicos em seres humanos, animais, plantas e no meio ambiente, notadamente como forma de profilaxia de acidentes e intoxicações (Sampaio, 1978). Esse rol de exigências fez com que a prescrição de receituário agronômico se tornasse prioridade para os ambientalistas.

Ao mesmo tempo, essa racionalização crítica do uso intensivo dos agrotóxicos contribuiu para reduzir a resistência ao controle dessa prática produtiva por meio de políticas públicas. Até 1978, o bloco de recomendações técnicas era o único instrumento de prescrição de agrotóxicos, muitas vezes utilizado apenas para ressaltar a necessidade impreterível do produto. Impulsionado pelo movimento em prol da restrição do uso de agrotóxicos organoclorados e dos altamente tóxicos, o Conselho Regional de Engenharia e Arquitetura e Agronomia do Rio Grande do Sul (Crea-RS) aprovou o Ato n. 2/1973, disciplinando a necessidade de uma Anotação de Responsabilidade Técnica (ART), que é considerada o embrião do receituário agronômico no Rio Grande do Sul. Com a ocorrência crescente de acidentes e agressões ambientais envolvendo o uso de agrotóxicos, as entidades de classe dos agrônomos organizaram-se a ponto de que a Empresa de Assistência Técnica e Extensão Rural do Rio Grande do Sul (Emater-RS) determinasse a emis- são do receituário agronômico nas propriedades rurais assistidas pela empresa sempre que houvesse necessidade do uso de agrotóxicos. Em 1978, o Banco do Brasil determinou, por meio da Carta n. 2.697/1978, que as verbas destinadas aos tratamentos fitossanitários somente poderiam ser liberadas mediante apresentação da receita agronômica (Alves Filho, 2002).

A resposta do Poder Executivo às demandas do fórum veio dois meses depois, com a edição do Decreto-Lei n. 30.787/1982, o qual dispõe sobre o uso de agrotóxicos à base de organoclorados no estado. No entanto, ela foi considerada insuficiente por proibir apenas o uso de tais produtos, não se estendendo ao comércio, o que traria dificuldades práticas para a fiscalização. Avaliou-se que a norma era circunscrita ao agricultor, o elemento mais frágil do ciclo, isentando as empresas que fabricavam ou comercializavam os insumos. Com isso, o fórum passou a defender a instituição do receituário agronômico para todos os agrotóxicos, independentemente de sua classificação toxicológica. Novamente, devido às pressões realizadas, o Poder Executivo viu-se obrigado a acatar o pleito. Em agosto de 1982, editou o Decreto Estadual n. 30.811, que tornou obrigatória a prescrição do receituário agronômico no comércio de "defensivos agrícolas".

Embora tais regulamentos tenham albergado temas importantes, a utilização do conceito defensivo agrícola revela a permanência da racionalidade proposta pela "Revolução Verde", contrariando

\footnotetext{
${ }^{3}$ Entende-se por processo semiotécnico "um conjunto de procedimentos que, através de informes, informações, sinais, etc., conduzem o profissional ao conhecimento do problema e sua origem (diagnóstico etiológico). Na elaboração do R.A., procura-se, em última análise, conhecer as origens de um processo que possa comprometer a cultura (etiológica). Em muitos casos, vários são os agentes de comprometimento (fungos, bactérias, pragas, vírus, problemas de solo, etc.); neste caso, estamos frente à possibilidade da obtenção de um diagnóstico multietiológico. A obtenção destas diferentes variações do diagnóstico constitui o fator primordial na confecção de um R.A.” (Sampaio, 1978).
} 
interpretações críticas quanto ao uso desse termo. Adilson Paschoal, professor de ecologia da Universidade de São Paulo (USP), foi pioneiro ao nomear esses insumos como agrotóxicos. De acordo com o autor,

A expressão defensivo agrícola ecologicamente é uma utopia, uma vez que os produtos ali integrantes não podem ser encarados como instrumentos de defesa, mas sim de destruição e perturbação do equilíbrio da biosfera. Diante da ausência de uma terminologia mais adequada, sugere-se o termo agrotóxico, que tem sentido geral para incluir todos os produtos químicos usados nos agroecossistemas para combater pragas e doenças. (Paschoal, 1979)

As conquistas pontuais obtidas com os Decretos n. 30.878/1982 e n. 30.811/1982 não exauriram os debates ambientais na Comissão de Direitos Humanos da Assembleia Legislativa. Esta passou a pleitear um sistema de controle dos agrotóxicos, especialmente quanto ao comércio de produtos importados que eram proibidos ou restritos nos países de origem. Isso poderia ser realizado somente por lei estadual específica, que deveria conter certas demandas. Ferrari (1985) resumiu-as da seguinte forma:

1 - a proibição da distribuição e comercialização dos produtos agrotóxicos que, resultantes de importação, não tivessem uso autorizado nos países de origem;

2 - a distribuição e comercialização dos agrotóxicos no Rio Grande do Sul estariam condicionadas a prévio cadastramento junto ao Departamento de Meio Ambiente da Secretaria Estadual de Saúde e Meio Ambiente.

3 - as entidades associativas, legalmente constituídas, terão o direito de solicitar a impugnação do cadastramento dos agrotóxicos, mediante argumentos fundamentados e analisados por laudo técnico;

4 - ampliar a abrangência do receituário agronômico para os produtos biocidas e de outra natureza, utilizados em zootecnia, pecuária e silvicultura; os receituários só teriam validade se expedidos por técnicos não vinculados a estabelecimentos produtores, manipuladores ou comercializadores de agrotóxicos e outros biocidas; 5 - as Comissões Técnicas da Assembleia Legislativa tinham o direito de solicitar a realização de análises físicas, químicas e biológicas, de parte dos laboratórios do Estado, visando detectar contaminação por qualquer substância em águas e alimentos, além de cópias de análises já efetuadas.

Com base nos pontos defendidos na Comissão de Direitos Humanos, construiu-se o Projeto de Lei n. 155/1982, redigido pelo fórum e proposto pelo Deputado Estadual Antenor Ferrari (MDB-RS) em outubro de 1982. Como ressaltou o deputado em entrevista concedida aos autores deste artigo,

Eu fui portador daquilo que a sociedade construiu (...) A redação surgiu da reunião dos ambientalistas. Produziram a lei e as justificativas, à dez mãos, vinte mãos, chegando-se a um consenso, aprovado na íntegra. Não foi um trabalho produzido pelos deputados que integraram a comissão. Também por eles, mas todos produziram em conjunto. Saiu das mãos da sociedade civil organizada e Lutzenberger, Sebastião Pinheiro, Flávio Lewgoy, Magda Reiner, entre outros, foram pessoas que centraram a discussão (Ferrari, 2013).

Esse projeto de lei, construído com a participação de representantes de diversas entidades envolvidas na questão, inclusive da Federação das Associações de Engenheiros Agrônomos do Brasil $(\text { Faeab })^{4}$, estabeleceu avanços significativos e iné-

\footnotetext{
${ }^{4}$ A proposta de implantação do receituário agronômico também sofria críticas dos ambientalistas. Para eles, o receituário agronômico poderia servir para um incremento no uso de agrotóxicos, e não propriamente na sua redução. Assim, "a luta desenvolvida pela Faeab, a favor da implantação do receituário agronômico tinha um alcance maior do que a simples adoção de um controle de vendas por receita" (Alves Filho, 2002).
} 
ditos no país no que tange ao controle da comercialização e do uso dos agrotóxicos, entre os quais destacam-se os seguintes:

a) condicionou a distribuição e a comercialização de produtos agrotóxicos, se resultantes de importação, a uso autorizado nos países de origem $\left(\operatorname{art.} 1^{\circ}, \S 2^{\circ}\right.$ ); b) instituiu a obrigatoriedade de realização e publicidade da classificação toxicológica do produto, bem como cadastro na Secretaria de Saúde e Meio Ambiente (art. $1^{\circ}, \S 3^{\circ}, \mathrm{b}$ e art. $1^{\circ}, \S 4^{\circ}$ );

c) inaugurou o direito das entidades civis para impugnar registros de produtos (art. $4^{\circ}$ ), dispositivo que representa o espírito democrático da lei estadual, pois "pela primeira vez uma lei introduziu o controle social em matéria de saúde pública" (Ferrari, 1985); d) reiterou o dispostos nos Decretos n. 30.878/1982 e n. 30.811/1982, mantendo a obrigatoriedade do receituário agronômico, que foi condicionada à inexistência de vínculo entre o técnico responsável e os estabelecimentos produtores, manipuladores ou comercializadores de agrotóxicos e outros biocidas (arts. $6^{\circ}$ e $7^{\circ}, \S 4^{\circ}$ ).

O Projeto de Lei n. 155/1982 foi aprovado por maioria na Assembleia Legislativa do Estado em dezembro de 1982 e encaminhado para a sanção do governador do estado, José Augusto Amaral de Souza (Arena-RS). Ferrari (2013) salientou, em entrevista, que "o PL foi aprovado por maioria. O líder da bancada do governo, dentre outros ligados a ele, votaram contra, mas não houve sustentação oral porque era uma demanda social muito forte".

O Diário Oficial do estado publicou a Lei n.
7.747/1982 contendo cinco vetos do Poder Executivo. Entre eles, os que tratavam justamente das reivindicações dos ambientalistas, como vedação da distribuição e comercialização de agrotóxicos importados, cujo uso fosse proibido no país de origem $^{5}\left(\operatorname{art.~}^{\circ}, \S 2^{\circ}\right)$ da possibilidade de convênios entre o poder público e universidades ou centros de pesquisas, para análises dos produtos, cujo ônus seria repassado para a empresa interessada na comercialização (art. $1^{\circ}, \S 5^{\circ}$ ); e a impugnação por entidades sociais quanto ao cadastramento de agrotóxicos (art. $4^{\circ}$ ).

Os vetos foram submetidos às vésperas do recesso parlamentar e figuraram como uma das ações finais do governo Amaral de Souza. É interessante observar que ele mesmo sancionou os Decretos n. 30.878/1982 e n. 30.811/1982, que impuseram restrições ao comércio desses insumos. Essa conduta contraditória - sancionar os decretos, mas vetar os dispositivos legais - é interpretada por Antenor Ferrari como resultado da pressão popular que o coagiu a elaborar os decretos, notadamente pela poluição do Rio Guaíba (Ferrari, 2013).

Souza foi o último governador do regime ditatorial, uma vez que em novembro de 1982 ocorreram as eleições diretas, nas quais Jair Soares (PDS) foi eleito. Todavia, embora a Arena tenha elegido seu sucessor para o governo do estado, em detrimento do candidato Pedro Simon, o PMDB registrou maioria na Assembleia Legislativa, o que foi fundamental para a revisão dos vetos propostos. A

\footnotetext{
${ }^{5}$ A Andef arguiu a inconstitucionalidade desse dispositivo, regulamentado pelo Decreto n. 32.854/1988. Contudo, a Adin sequer foi conhecida, por ter sido proposta em 1993, portanto depois de promulgada a Constituição Federal. (STF - ADI-MC: 847 RS. Relator: Néri DA Silveira. Data de julgamento: 10/03/1993, Tribunal Pleno. Data de publicação: DJ 08-04-1994). O dispositivo permanece em vigor. Entretanto, em 2010, o Partido Democratas ajuizou a Arguição de Descumprimento de Preceito Fundamental (ADPF) n. 221, na qual contesta a lei e os decretos do Rio Grande do Sul por restringirem a distribuição e a comercialização de agrotóxicos e biocidas importados em território gaúcho. O processo se encontra concluso com o relator Dias Toffoli desde 12/2016 e, portanto, ainda não há decisão definitiva.
} 
posse ocorreu em março de 1983 e a apreciação dos vetos apresentados pelo Poder Executivo ocorreu em abril do mesmo ano. Foi nesse contexto que os parlamentares, por unanimidade, decidiram rejeitá-los, mantendo a redação da lei tal qual a elaborada pelo coletivo de entidades civis com a Comissão de Direitos Humanos, em 1982. Vale ressaltar que Antenor Ferrari a sancionou, como presidente da Assembleia Legislativa Estadual (Ferrari, 2013).

Evidencia-se, portanto, que a ação política em prol do maior rigor no controle dos agrotóxicos no país iniciou-se em nível estadual, nos espaços institucionais que pautaram regulação própria sobre tais produtos. Para os ambientalistas, a criação dessas leis significou uma conquista no sentido de se criar mecanismos sociais e políticos de controle do risco inerente ao uso intensivo desses insumos. Já para a indústria de agrotóxicos, significou a restrição do comércio de seus produtos, o que desencadeou uma série de recursos jurídicos, pressões políticas e estratégias de comunicação por parte de suas entidades de classe (Dreyer, 2004).

\section{As estratégias de resistência da Associação Nacional de Defensivos Agrícolas}

Contrária às normas inauguradas no Estado do Rio Grande do Sul, a Associação Nacional de Defensivos Agrícolas (Andef) apoiou a Procuradoria-Geral da República nas representações de inconstitucionalidade n. 1.153/1985 e n. 1.150/1985 perante o Supremo Tribunal Federal (STF). Nelas, sustentou-se a inconstitucionalidade da lei estadual e dos Decretos n. 30.787/1982 e n. 30.811/1982, respectivamente. As razões processuais arguidas, em resumo, foram: a) tratava-se de normas gerais de defesa e proteção da saúde, cuja competência para legislar seria da União, e não dos estados; b) a lei estabelecia limitações ao comércio interestadual, interferindo na produção e no consumo ao condicionar a distribuição e a comercialização dos agrotóxicos a prévio cadastramento em órgão estadual; c) o estado não poderia exigir classificação toxicológica e relatório técnico aos produtos já existentes no mercado estadual; d) a fiscalização de inseticidas e fungicidas seria competência exclusiva da União.

A tese central do pleito da Andef foi, portanto, a de incompetência dos estados em legislar e fiscalizar questões sobre agrotóxicos, cujo atributo seria exclusivo da União. Contra ela, tanto a Procuradoria do Estado quanto a Assembleia Legislativa posicionaram-se em defesa da constitucionalidade da lei gaúcha sob o argumento da competência supletiva dos estados, disposição prevista no art. 89, XVII, letra $c$, da Constituição da República (Ferrari, 2013). Essa impugnação sustentou que a lei estadual, ao definir os produtos regulados como agrotóxicos, não buscou "esgotar uma definição genérica pelo que se deve entender por agrotóxico, mas somente limitar a abrangência do édito nos produtos que, por sua natureza, possam, de uma ou outra forma, prejudicar, por sua utilização ou má utilização, a saúde humana ou o equilíbrio ecológico" (Rio Grande do Sul, 1983). Ferrari defende que os questionamentos judiciais da Andef "tiveram o claro propósito de evitar os prejuízos que as empresas acumulariam com a vigência do sistema de controle do comércio e uso dos agrotóxicos. Até mesmo porque, a nível federal, não existe qualquer restrição que represente urna ameaça aos seus interesses" (Ferrari, 1985).

Pari passu à representação proposta no STF, em setembro de 1983, as empresas do ramo im- 
petraram mandado de segurança perante a Vara da Fazenda Estadual, no intuito de suspender a aplicação da Lei dos Agrotóxicos. Em seu parecer, o Ministério Público Estadual afirmou que

Não houve usurpação legislativa no concernente a legislar sobre normas gerais de defesa e proteção à saúde, nem tampouco as normas editadas foram de encontro à legislação federal pertinente à espécie; veio, ao invés, preencher lacunas no tocante ao controle e fiscalização dos produtos agrotóxicos.

Seguindo esse parecer, a Vara da Fazenda Estadual decidiu pela constitucionalidade da lei gaúcha de agrotóxicos (Ferrari, 1985, p. 64).

Com base na proliferação de leis estaduais (apresentadas na próxima seção) e da instabilidade comercial em se aguardar a decisão a ser proferida pelo STF, que já tramitava há mais de ano, e ante as dúvidas quanto ao seu resultado, a indústria química reforçou outra tática além da tutela judicial: buscar respaldo legislativo ${ }^{6}$. A indústria passou a defender a necessidade de nova lei federal, em substituição ao Decreto n. 24.114/1934, que centralizasse os poderes de controle na União, retirando-os dos estados (Bull \& Hathaway, 1986).

As pressões políticas da indústria refletiram nas ações do governo federal, que elaborou um projeto de lei de agrotóxicos, redigido por uma comissão informal composta por cerca de 50 especialistas governamentais e encaminhado ao Presidente Figueiredo por meio da Exposição de Motivos Interministerial n. 735/1984, o qual foi submetido à apreciação do Congresso Nacional no dia 15 de outubro (Bull \& Hathaway, 1986). Esse projeto apresentava diversos avanços: divisão de competências para controle e fiscalização dos produtos "fitossanitários" entre os ministérios de Agricultura, de Saúde, do Interior e do Trabalho (art. $6^{\circ}$ ); validade de 5 anos para os registros (art. $7^{\circ}, \S 2^{\circ}$ ) e estabelecimento de taxas para registro e reavaliação dos insumos $\left(\operatorname{art.} 15^{\circ}, \S 3^{\circ}\right)$. Também disciplinou as responsabilidades administrativas, civis e penais pela produção, prescrição, comercialização e pelo uso de agrotóxicos, estabelecendo multas para as infrações. No entanto, foi muito criticado por centralizar na União a competência de avaliar e registrar os agrotóxicos, o que afetaria diretamente as leis estaduais aprovadas. Como observam Bull \& Hathaway (1986, p. 188),

os governadores da maioria dos Estados - muitos deles do PDS - já haviam sancionado leis estaduais sujeitas a serem derrubadas por esta iniciativa federal. Representantes de secretários de vários destes governos reuniram-se diversas vezes em outubro e novembro, no Conselho Interestadual de Agrotóxicos e Alternativas Agrícolas, para discutirem detalhadamente o projeto de lei e encaminharem ao Congresso suas próprias propostas. Uma das maiores manifestações do repúdio nacional e suprapartidário, inclusive, foi a moção de protesto enviada ao Presidente pelos secretários de Saúde de todos os Estados da União contra o envio "acordado" do anteprojeto de lei dos agrotóxicos.

Além disso, o projeto não constituiu normas para as avaliações toxicológicas, agronômicas e ambientais dos agrotóxicos, mantendo-as como

\footnotetext{
${ }^{6}$ Houve indícios de tráfico de influência no Brasil, como no "Escândalo dos Agrotóxicos", no qual a Revista Veja noticiou a tentativa de suborno feita por um representante da Andef ao chefe do gabinete da Secretaria de Agricultura do Paraná para que a lei estadual do Paraná não fosse aplicada (Revista Veja, 1984).
} 
discricionárias pelo seu art. $4^{\circ}$, que atribuiu esses parâmetros ao Poder Executivo Federal. A apresentação desse projeto acabou obstruída por congressistas contrários ao texto. Tal obstrução afetou não só o projeto, mas também barrou diversas proposições do Executivo, até que em 14 de novembro o presidente cedeu e retirou seu projeto de lei sobre os agrotóxicos. Desse modo, o tema permaneceu regulado pelo Decreto n. 24.114/1934, embora fosse consenso a necessidade de uma nova lei (Bull \& Hathaway, 1986).

Em maio de 1985, o STF decidiu pela parcial inconstitucionalidade da Lei de Agrotóxicos do Rio Grande do Sul. Alguns dispositivos importantes de controle técnico e social foram validados, como a obrigatoriedade do receituário agronômico e o direito de entidades da sociedade civil de impugnar os registros dos produtos na Secretaria Estadual de Saúde. Ainda, a decisão reconheceu a competência de se legislar supletivamente sobre o tema. Entretanto, o estado não poderia denominar tais produtos como agrotóxicos, nem realizar o registro e o cadastramento de produtos, nem estabelecer normas e critérios para classificação toxicológica, por ser entendido como competência da União ${ }^{7}$.

Ainda que considerável, a atuação da Andef não impediu a disseminação de leis estaduais em outras unidades da federação. Os debates ocorridos no Estado do Rio Grande do Sul tiveram repercussões significativas na esfera federal, a tal ponto que o controle do uso dos agrotóxicos passasse a ser incorporado na agenda da Presidência da República.

\section{As repercussões da Lei de Agrotóxicos do Rio Grande do Sul em nível nacional}

O processo de construção da Lei n. 7.474/1982 refletiu na tratativa do tema em outros estados da federação, especialmente porque parlamentares gaúchos compunham a entidade denominada União Parlamentar Interestadual, que se reunia uma ou duas vezes ao ano (Ferrari, 2013). Nela havia uma Comissão do Meio Ambiente, composta por Antenor Ferrari e outros deputados. Estes levaram a iniciativa para seus estados, que criaram suas respectivas leis, como Paraná (Lei n. 7.827/1983), Santa Catarina (Lei n. 6.452/1984), Minas Gerais (Lei n. 4.002/1984), São Paulo (Lei n. 4.002/1984) e Espírito Santo (Lei n. 3.706/1984).

Com o fim da ditadura militar, a Assembleia Nacional Constituinte foi organizada em 1986, na

\footnotetext{
7 "Representação de inconstitucionalidade da Lei Estadual n. 7.747, de 22 de dezembro de 1982, em conjunto com os Decretos n. 30.787, de 22/7/1982, e 30.811, de 23/8/82, todos do Estado do Rio Grande do Sul. Competência constitucional da União para legislar sobre normas gerais de defesa e proteção à saúde (artigo 8, XVII, 'c', da C.F.), e, supletivamente, dos Estados (parágrafo único do artigo $8^{\circ}$ ). Supremacia da Lei Federal. Limites. Caráter supletivo da lei estadual, de modo que supra hipóteses irreguladas, preenchendo o 'vazio', o 'branco' que restar, sobretudo quanto às condições locais. Existência, 'in casu', de legislação federal que regula a espécie. Inconstitucionalidade da definição de agrotóxicos e outros biocidas por lei estadual; ou da fixação de normas gerais e parâmetros para a classificação toxicológica. Competência da União para estabelecer proibições à produção, comércio e consumo de mercadorias que contenham substancias nocivas. Poder de polícia do Estado - limites. Representação procedente, em parte. Inconstitucionalidade, na lei 7.747, de 22/12/1982: do $\S 1^{\circ}$ do artigo $1^{\circ}$; da alínea 'a' do $\S 3^{\circ}$ do artigo $1^{\circ}$; da parte final da alínea 'b'; do $\S 3^{\circ}$ do art. $1^{\circ}$ : 'obedecendo, no mínimo, as normas e parâmetros estabelecidos no anexo i, da presente lei'; da parte final da alínea 'c' do $\S 3^{\circ}$ do artigo $1^{\circ}$ : 'contendo, no mínimo, os dados constantes do anexo ii, desta lei’; da alínea 'd' do $\S 3^{\circ}$ do artigo $1^{\circ}$; do $\S 4^{\circ}$ do artigo $1^{\circ}$; do artigo $3^{\circ}$ - 'caput'; do artigo $5^{\circ}$ (como consequência da inconstitucionalidade do decreto $30.787 / 82$ ); no artigo $7^{\circ}$, a parte final: 'entendendo-se como tais os zootecnistas, médicos veterinários e engenheiros florestais'; o parágrafo único do artigo $7^{\circ}$; os anexos I e II.’” (STF, Supremo Tribunal Federal. Representação n. 1.153- RS. Tribunal Pleno, 16/05/1985, grifo nosso)
} 
qual a regulação social tornou-se tema proeminente da agenda política, com destaque para a proteção ambiental e os direitos do consumidor. Estes passaram a ser objeto da ordem constitucional editada em 1988, o que fortaleceu o ambiente jurídico para a elaboração de uma legislação federal de controle do uso de agrotóxicos, capaz de substituir um decreto regulamentador historicamente defasado (Decreto n. 24.114/1934), então em vigor.

A mobilização em nível federal ocorreu a partir da nomeação do gaúcho e também PMDBista Pedro Simon como ministro da Agricultura pelo Presidente José Sarney, em 1985. Com isso, quatro meses depois da aludida decisão do Supremo, o ministro expediu a Portaria n. 329/1985, que determina a proibição do uso, do comércio e da distribuição de organoclorados em todo o território nacional ${ }^{8}$.

Em 1986, Simon nomeou uma comissão especial para elaborar o anteprojeto de lei sobre agrotóxicos. Essa atitude figurou como resposta à demanda social por uma regulação de agrotóxicos mais rígida, especialmente por parte de sua base política, cujo posicionamento sobre o tema foi consolidado pela promulgação da Lei Estadual n. 7.747/1982, do Rio Grande do Sul.

A comissão especial foi estabelecida pelo Decreto n. 91.633, de 9 de setembro de 1985, alterado pelo Decreto n. 91.910, de 12 de novembro de 1985, ambos subscritos pelo Presidente José Sarney. O art. $2^{\circ}$ do Decreto n. 91.633/1985 demonstrava a pluralidade de interesses representados, pois era composto pelos Ministérios da Agricultura, da
Saúde, do Trabalho, da Indústria e do Comércio, do Desenvolvimento Urbano e Meio Ambiente, da Educação, do Interior, da Ciência e Tecnologia, e da Secretaria de Planejamento da Presidência da República (Seplan), bem como por outros entes públicos e diversas entidades sociais ligadas ao tema. Com a publicação do Decreto n. 91.910/1985, acresceu-se aos debates membros da Federação Nacional das Associações de Técnicos Agrícolas (Fenata), da Organização das Cooperativas Brasileiras (OCB) e do Sindicato Nacional da Indústria de Defensivos Animais (Sindam).

Dos debates realizados na referida comissão sobreveio o anteprojeto encaminhado à Presidência da República por meio da Exposição de Motivos n. 005, em 13 de janeiro de 1986, pelo então ministro da Agricultura. Posteriormente, com a nomeação de Iris Rezende Machado para o Ministério da Agricultura, em fevereiro de 1986, o anteprojeto elaborado pela comissão especial foi reexaminado, sob o argumento de sanar inconstitucionalidades. Por meio da Exposição de Motivos n. 100, de 24 de junho de 1986, foi submetido à consideração da Presidência da República. O projeto permaneceu por mais de dois anos parado na Casa Civil e só veio a ser retomado com a edição do Decreto n. 96.944, em outubro de 1988, o qual criou o Programa de Defesa do Complexo de Ecossistemas da Amazônia Legal, conhecido como Programa Nossa Natureza.

O Programa Nossa Natureza foi originário das lutas dos seringueiros da Amazônia, em prol da preservação de seu modo de vida e pela defesa do

\footnotetext{
8 "O Ministro do Estado da Agricultura, no uso das atribuições que lhe confere o Capítulo VI e, especificamente, o art. 143 do Regulamento aprovado pelo Decreto n. 24.114, de 12 de abril de 1934, e considerando a necessidade de resguardar a saúde humana e animal e o meio ambiente da ação de agrotóxicos, comprovadamente da alta persistência e/ou periculosidade resolve:

$1^{\circ}$ - Proibir, em todo o território nacional, a comercialização, o uso e a distribuição dos produtos agrotóxicos organoclorados, à agropecuária dentre outros(...)" (Brasil, 1985)
} 
meio ambiente 9 . No entanto, na prática, foi uma resposta internacional do Brasil ao assassinato do líder Chico Mendes, em 1988 (Richard, 2013). A situação político-ambiental era bastante conflituosa à época. Um ano após Chico Mendes receber o Prêmio Global 500 das Nações Unidas e o Prêmio Por uma Vida Melhor, conferido pela Sociedade Americana para Ecologia, ele foi assassinado. A morte do ecologista brasileiro teve repercussões internacionais, ocupando a primeira página do jornal norte-americano The New York Times, que publicou a questão na matéria “The Brazilian Who Fought to Protect Amazonia Is Killed" (Simons, 1988).

O Programa Nossa Natureza não estava inicialmente ligado à proposição legislativa sobre o controle de agrotóxicos. No entanto, a repercussão internacional da morte de Chico Mendes demandou um posicionamento ativo do governo brasileiro em prol da proteção ambiental ${ }^{10}$. Esse cenário contribuiu para que o anteprojeto debatido pela comissão especial, designada em 1986, retornasse à agenda política como prioridade nacional. A proposta passou a ser tratada em regime de urgência pelo Poder Executivo, que o incluiu no Programa Nossa Natureza, por meio da Mensagem n. 165/1989. A partir de então, o anteprojeto foi adaptado às diretrizes ambientais formuladas no âmbito do Decreto n. 96.944/1988.

Em 24 de abril de 1989, o Poder Executivo submeteu à deliberação do Congresso Nacional o reexame desse projeto, que recebeu a alcunha de Projeto de Lei n. 1924/1989. A exposição de motivos desse projeto contou com as assinaturas dos ministros de Estado de Agricultura, do Estado do Interior e do Ministro de Estado Secretário-Geral da Secretaria de Assessoramento da Defesa Nacional. Por serem secretarias e ministérios ligados à soberania da nação, reforça-se o intuito da criação da lei como resposta às pressões internacionais pela proteção ao meio ambiente (Brasil, 1989).

A Mesa Diretiva distribuiu o projeto de lei para análise da Comissão de Constituição e Justiça e Redação, da Comissão de Agricultura e Política Rural, da Comissão de Economia, Indústria e Comércio. As comissões analisaram todas as 28 emendas parlamentares apresentadas ao projeto e emitiram pareceres sobre a pertinência do projeto de lei (Brasil, 1989).

A Comissão de Agricultura e Política Rural foi a primeira a apresentar seu parecer. Apesar de sua concepção permear o discurso do livre comércio e da ampla concorrência, o Relator Deputado Jovani Massini defendeu a necessidade de o Poder Público regular o mercado, embora sob uma ótica não "policialesca":

faz-se necessária uma postura despida de preconceitos de qualquer ordem, imune ao receio de atribuir aos

\footnotetext{
${ }^{9}$ Essa preocupação reflete-se no objetivo do programa, disposto em seu art. $1^{\circ}$, inciso VI: "proteger as comunidades indígenas e as populações envolvidas no processo de extrativismo".

${ }^{10} \mathrm{O}$ próprio ex-Presidente José Sarney assume essa pressão internacional em seu site: "Em agosto de 1988 foram queimados, por dia, cerca de mil quilômetros quadrados de mata. As críticas e a pressão internacional aumentaram sobre o Brasil e levaram a uma reação do governo. Ainda em 1988, Sarney lançou o Programa de Defesa do Complexo de Ecossistemas da Amazônia Legal, o chamado 'Programa Nossa Natureza', com a finalidade de estabelecer condições para a utilização e a preservação do meio ambiente e dos recursos naturais renováveis na Amazônia Legal”. In: Meio Ambiente no Governo Sarney. Disponível em: <http://josesarney.org/o-politico/presidente/politicas-do-governo/meio-ambiente-no-governo-sarney/>.
}

Acesso em: 12 out. 2013. 
poderes públicos os instrumentos para a defesa dos interesses gerais de preservação da saúde e do meio ambiente, mas também infensa a uma mentalidade policialesca frente aos setores produtivos. Neste campo, a ponderação e o equilíbrio são essenciais, cabendo lembrar que a sabedoria dos gregos deu o mesmo nome-phar makon-ao remédio e ao veneno, fazendo residir a diferença entre ambos na quantidade da dosagem. (Brasil, 1989, p. 82-83).

A Comissão de Constituição e Justiça e Redação fez apreciações formais com relação à legitimidade da propositura do projeto de lei, além da disposição da redação do texto normativo. Além disso, acolheu a constitucionalidade e juridicidade de todas as emendas materiais propostas ao projeto e não fez qualquer acréscimo quanto à materialidade do texto (Brasil, 1989).

O parecer exarado pela Comissão de Economia, Indústria e Comércio refutou expressamente o principal argumento da indústria de agrotóxicos na justificativa do uso desses produtos, que é o de acabar com a fome mundial pelo aumento na produtividade dos alimentos. Registrou que "a causa da miséria não é a escassez de alimentos, mas a pobreza de populações crescentes (a própria explosão, demográfica no $3^{\circ}$ mundo, e, ao mesmo tempo, sua causa e consequência) sem dinheiro para comprar e sem acesso aos instrumentos e meios para produzirem os seus alimentos" (Brasil, 1989, p. 180). Revelou também apreensão com a falta de rigor da legislação vigente e as repercussões disso no comércio internacional dos produtos agrícolas brasileiros. $\mathrm{O}$ argumento era de que os países desenvolvidos poderiam inibir as exportações de produtos brasileiros pela ausência de controle sobre tais substâncias, aplicadas pelos agricultores brasileiros praticamente sem fiscalização (Brasil, 1989).

\begin{abstract}
A rigidez com que são efetuadas as análises de resíduos de pesticidas e agroquímicos em geral nos produtos agropecuários importados pelos países mais desenvolvidos, podem inibir, de maneira perigosa e extremamente prejudicial, as exportações de produtos brasileiros. Não legislar, impondo preocupações que preservem a saúde pública e o nível qualitativo de nossas exportações, além, de demonstrar irresponsabilidade, pode acarretar danos incalculáveis para o nosso comércio exterior. (Brasil, 1989, p.182).
\end{abstract}

A lógica adotada por essa Comissão, que parece incoerente com os anseios de seus representados, é explicável pela proximidade do Relator Deputado Artur Lima Cavalcanti com membros ambientalistas da Agapan, como Sebastião Pinheiro e Lutzenberger, que o auxiliaram na redação da Lei Pernambucana de Agrotóxicos, da qual foi autor ${ }^{11}$. Por esse motivo, seu parecer no Projeto de Lei n. 1.924/1989 contou com a aprovação de grupos ambientalistas (Pinheiro et al., 1998).

Originário desse acordo, o Projeto de Lei n. 1.924/1989 foi aprovado pela Câmara dos Deputados em 15 de junho de 1989, seguindo para apreciação do Senado. No dia 6 de julho de 1989, em caráter revisório, o Projeto de Lei n. 1.924/1989 recebeu aprovação do Senado, sem modificações. Cinco dias depois, em 11 de julho de 1989, o Presidente José Sarney sancionou a Lei Federal n. 7.802/1989, que inaugurou a nova política de agrotóxicos do Brasil.

O novo texto legislativo introduziu importan-

\footnotetext{
${ }^{11}$ Como observa Sebastião Pinheiro, "Na Comissão de Economia, Indústria e Comércio recebeu outro substitutivo de autoria Lima Cavalcanti, PDT-PE na época, que, anteriormente, como deputado estadual por Pernambuco, havia elaborado cinco leis sobre meio ambiente, com a minha ajuda e do Lutzenberger. Entre elas a Lei Estadual de Agrotóxicos de Pernambuco" (Pinheiro et al., 1998, p. 26-27).
} 
tes avanços em relação ao decreto de 1934, ao instituir regras mais rigorosas para a concessão de registro aos agrotóxicos, baseado em análises de toxicidade ao meio ambiente e à saúde humana. A nova legislação passou a adotar oficialmente o termo agrotóxico para designar os produtos químicos voltados ao controle de organismos indesejados na produção agrícola. Determinou ainda a possibilidade de impugnação ou cancelamento do registro por solicitação de entidades representativas da sociedade civil; o cadastro de todos os agentes diretamente envolvidos no manuseio de agrotóxicos, desde os produtores até os aplicadores dos produtos; a obrigatoriedade do receituário agronômico para a venda de agrotóxicos; e as normas e os padrões das embalagens e rótulos dos produtos (Brasil, 1989).

Todas essas medidas já haviam sido previstas na Lei de Agrotóxicos do Rio Grande do Sul. Ao participaram ativamente na comissão de elaboração do projeto de lei federal, os representantes da Faeab, com destaque para o agrônomo Sebastião Pinheiro e o professor Flávio Lewgoy, que atuavam também na Agapan, lograram incorporar os principais avanços da legislação estadual ao nível federal. Cabe destacar que a atuação dessas pessoas foi determinante para a inclusão da análise de perigo no registro de novos produtos (Lewgoy, 2013; Pinheiro, 2013). Isso significa que agrotóxicos com efeitos carcinogênicos, teratogênicos e desreguladores hormonais devem ser proibidos, independentemente da dose utilizada. Esse dispositivo, que tem caráter de precaução, só foi adotado pelos países da União Europeia no Regulamento 1.107, de 2009, em vigor a partir de junho de 2011.

\section{Considerações finais}

Evidenciamos que as pautas defendidas no governo federal nos anos 1970 e 1980 revelam a configuração de polos contrários nos debates sobre agrotóxicos: de um lado, a representação de interesses das empresas fabricantes desses insumos; de outro, a emergência de um movimento ambientalista crítico ao modelo agrícola adotado no país. Essa polarização de interesses foi tratada com base na apresentação das táticas adotadas pelos grupos de interesse mais representativos (Agapan e Andef), ao demonstrar como eles influenciaram o processo de formulação de políticas públicas que antecederam a legislação federal.

Com base em sua força econômica, a indústria de agrotóxicos mostrou-se influente na delimitação de políticas públicas, contrapondo-se de diversas formas à instauração de uma política regulatória que restringisse seu espaço de atuação no mercado nacional. Atualmente a Andef, hoje Associação Nacional de Defesa Vegetal, tem um discurso diferente do das décadas de 1970 e 1980, quando então denominava-se Associação Nacional de Defensivos Agrícolas. Não por acaso, ao longo dos anos, ela incorporou o discurso de parte do movimento ambientalista, em especial quanto à necessária qualidade e segurança dos alimentos. Essa aparente transformação da atuação da Andef está associada a um novo contexto sociopolítico, no qual saúde e meio ambiente passaram a ser elementos legitimadores associados a uma alimentação saudável.

Nesse contexto, a atuação da Agapan mostrou-se fundamental para a construção de um ambiente permeável às preocupações com os riscos do uso intensivo de agrotóxicos na agenda política, 
tanto em nível estadual quanto federal. Os debates promovidos em nível estadual tiveram repercussões significativas na agenda federal, a ponto de que o controle do uso dos agrotóxicos passasse a ser incorporado na agenda da Presidência da República, a qual culminou com a criação da Lei Federal de Agrotóxicos.

Assim como a contaminação do Rio Guaíba contribuiu para a inserção do controle dos agrotóxicos na agenda política do Rio Grande do Sul, o assassinato de Chico Mendes e a instituição do Programa Nossa Natureza explicam, em grande parte, o resgate do anteprojeto de lei federal do limbo político. A retomada dessa proposta em regime de urgência e sua aprovação no Congresso Nacional, contando inclusive com o apoio de representantes mais conservadores do setor produtivo, revela um momento histórico inusitado do país. Nesse momento houve uma convergência de ao menos três fatores determinantes: a aprovação de uma constituição que incorporou os direitos fundamentais de cidadania, notadamente em termos de direitos do consumidor e de respeito e preservação da saúde humana e do meio ambiente; a pressão externa internacional para que o Brasil incorporasse a questão ambiental à sua agenda política; e a experiência do movimento ambientalista brasileiro, protagonizado pela Agapan, na construção de marcos legais de controle do uso de agrotóxicos.

Em que pese os avanços significativos de uma legislação, cuja construção foi uma resultante da participação e do aprendizado da sociedade civil organizada, sua implementação apresenta-se ainda fragilizada pela capacidade de resistência de grupos ligados ao setor produtivo. Um exemplo atual é a Arguição de Descumprimento de Preceito Fundamental (ADPF) 221, ajuizada no ano de 2010 pelo Partido Democratas, a qual permanece em trâmite no STF. A ação contesta a Lei n. 7.747/1982 e decretos do Rio Grande do Sul que restringem a distribuição e comercialização de agrotóxicos e biocidas importados em território gaúcho121212. No fim do ano de 2016, a Agapan foi incluída nos autos como amicus curiae, ou parte interessada, cuja finalidade é fornecer subsídios ao julgador, propiciando incremento na qualidade das decisões judiciais. A Agapan permanece atuante. Mas isso é outra história.

\section{Referências}

Alves Filho, J. P. Uso de agrotóxicos no Brasil: controle social e interesses corporativos. São Paulo: Annablume; FAPESP, 2002.

Bones, E.; Hasse, G. Pioneiros da ecologia: breve história do movimento ambientalista do Rio Grande do Sul. Porto Alegre: JÁ editores, 2007.

Brasil. Portaria Ministério da Agricultura n. 329 de 2 de setembro, 1985.

Brasil. Processo legislativo - projeto de Lei n. 1924/1989. Câmara dos Deputados. Brasília, 1989.

Bull, D.; Hathaway, D. Pragas e venenos: agrotóxicos no Brasil e no terceiro mundo. Petrópolis: Vozes, 1986.

Dreyer, L. Sinfonia inacabada: a vida de José Lutzenberger. Porto Alegre: Vidicom Audiovisuais edições, 2004.

Ferrari, A. Agrotoxicos: a praga da dominação. $2^{\mathrm{a}} \mathrm{ed}$. Porto Alegre, Mercado Aberto, 1985.

\footnotetext{
${ }^{12}$ A Lei Estadual n. 7.747/1982 e os decretos estaduais n. 32.854/1988 e n. 35.428/1994 dispõem que os agrotóxicos importados não podem ser cadastrados no órgão estadual de meio ambiente se não tiverem seu uso autorizado no país de origem. (STF, 2010)
} 
Ferrari, A. Entrevista concedida em 09 set. 2013 aos autores, via Skype.

Lewgoy, J. Entrevista concedida em 12 out. 2013 aos autores, via Skype.

Paschoal, A. D. Pragas, praguicidas e a crise ambienteProblemas e soluções. Rio de Janeiro, FGV, 1979.

Pinheiro, S. Entrevista concedida em 12 out. 2013, via Skype.

Pinheiro, S.; Youssef, N.; Luz D. A agricultura ecológica e a máfia dos agrotóxicos. Rio de Janeiro: Fundação Juquira Candirú, 1998.

Revista Veja. O lance obscuro. Edição n. 815, de 18 de abril de 1984.p. 58

Richard, I. Morte de Chico Mendes abre caminho para a questão ambiental no país. Agência Brasil, 20/12/2013. Disponível em: http://memoria.ebc.com.br/agenciabrasil / noticia/2013-12-20/morte-de-chico-mendes-abre-caminho-para-questao-ambiental-no-pais. Acesso em: 15 out. 2013.

Rio Grande do Sul. Assembleia Legislativa do Estado do. Parecer n. 1.141. Memorial ao STF. Celso Gaiger de 12/04/1983; Verena Nygaard, 04/1984, apud Ferrari, A. Agrotóxicos: a praga da dominação. p. 46
Sampaio, D. P. Receituário agronômico - conceitos, objetivos e elaboração. In: Fundamentos do receituário agronômico. Centro de estudos toxicológicos-RS, $1^{\circ}$ curso sobre fundamentos do receituário agronômico, CETREISUL/ FAEM/UFPEL. Sociedade de agronomia do rio grande do sul- conselho de desenvolvimento agropecuário do RS, 10 a 15 de abril de 1978.p.22

Simons, M. Brazilian who fought to protect amazon is killed. New York Times, 24/12/1988. Disponível em: http://www. nytimes.com/1988/12/24/world/brazilian-who-fought-to-protect-amazon-is-killed.html. Acesso em: 15 out. 2013.

STF - Supremo Tribunal Federal. Representação n. 1.153 - RS. Tribunal Pleno, 16/05/1985.

Viola, E. J. O movimento ecológico no Brasil (1974-1986): do ambientalismo à ecopolítica. Revista Brasileira de Ciências Sociais, 1(3), 1987. 